\title{
Short-term outcomes of laparoscopic versus open liver resection for hepatocellular carcinoma in elderly patients: A propensity score matching analysis
}

Kazuteru Monden ( $\triangle$ monden0319@yahoo.co.jp)

Fukuyama City Hospital

Hiroshi Sadamori

Fukuyama City Hospital

Masayoshi Hioki

Fukuyama City Hospital

Satoshi Ohno

Fukuyama City Hospital

Norihisa Takakura

Fukuyama City Hospital

\section{Research Article}

Keywords: Elderly patients, Laparoscopic liver resection, Propensity score matching, Short-term outcomes

Posted Date: December 17th, 2020

DOl: https://doi.org/10.21203/rs.3.rs-118776/v1

License: (c) (i) This work is licensed under a Creative Commons Attribution 4.0 International License. Read Full License 


\section{Abstract}

The number of elderly patients with hepatocellular carcinoma (HCC) requiring surgical treatment has been continuously increasing. This study aimed to examine the safety and feasibility of laparoscopic liver resection (LLR) versus open liver resection (OLR) for HCC in elderly patients at our institution in Japan.

Between 2010 and 2018, LLR and OLR were performed in 80 and 138 elderly patients (>70 years) who were diagnosed with HCC, respectively. Propensity score matching (PSM) analysis with covariates of baseline characteristics was applied. Intra- and postoperative data were evaluated in both groups.

After PSM, 56 patients who underwent LLR and OLR, respectively, were compared. No significant differences in demographic, clinical data, and operative times were observed. Blood loss (OLR: $327 \mathrm{~mL} ;$ LLR: $50 \mathrm{~mL} ; P<0.001$ ), length of postoperative hospital stay (OLR: 12 days; LLR: 7 days; $P<0.001)$, and time to start oral intake (OLR: 2 days; LLR: 1 day; $P<0.001)$ were significantly lower and shorter in the LLR group than in the OLR group. The incidence of complications over Clavien-Dindo class Illa was similar between both groups.

Our results suggest that advanced age alone is not a contraindication, and LLR can be a treatment option for elderly patients with HCC.

\section{Introduction}

Hepatocellular carcinoma (HCC) is one of the most common leading causes of cancer death worldwide [1]. The risk of developing HCC depends on the epidemiology of chronic viral hepatitis (type B and C), alcohol abuse, nonalcoholic steatohepatitis, autoimmune hepatitis, and aflatoxin exposure [2]. The currently recommended treatments, which include surgical resection, radiofrequency ablation, and liver transplantation, are considered curative treatments for HCC.

Since the first laparoscopic liver resection (LLR) was reported in 1992, reports on LLR as an option for surgical resection have been increasing and have spread worldwide [3]. Several studies reported that LLR resulted in shorter hospital stays, reduced blood loss, fewer complications, and earlier postoperative recovery than open liver resection (OLR) [4-6]. Furthermore, a metanalysis of comparative studies showed that LLR has favorable shortterm and long-term survival [5].

It is well known that the risk of developing HCC is age-dependent [7]; with increasing life expectancy, the number of elderly patients with $\mathrm{HCC}$ is expected to increase continuously, and the treatment for elderly patients remains a global issue. Elderly patients who may already be prescribed numerous medications have more comorbidities, such as chronic hypertension, diabetes mellitus, rhythm disturbance or stroke, renal insufficiency, pulmonary disease, and cancer history, than younger patients. Other age-related changes indicate a decline in liver and respiratory functions. Portal blood flow decreases in 30-40\% in participants over 71 years of age [8, 9], and liver volume decreases in $20-40 \%$ with age $[8,10]$. Therefore, elderly patients are more likely to have occlusive events, and their operative course needs more attention than that of younger patients. Nonetheless, several reports have indicated that OLR for elderly patients with HCC is safe and feasible [11-13]. Conversely, the benefits of laparoscopic surgery for elderly patients with HCC remain controversial.

To the best of our knowledge, limited studies on the risk of surgical complications or the safety and efficacy of LLR for HCC in elderly patients have been conducted [13-15]. Thus, this study aimed to examine the safety and 
feasibility of LLR for HCC in elderly patients using propensity score matching (PSM) analysis to reduce the effect of treatment or patient selection bias.

\section{Materials And Methods}

\section{Study patients and protocol}

Initially, 225 patients aged $\geq 70$ years with newly diagnosed HCC and who underwent LLR and OLR in our department between January 1, 2010, and December 31, 2018, were enrolled in the study. Collected data were retrieved from prospectively maintained databases. Three patients were excluded from the analysis because of hybrid laparoscopic surgery, and four underwent combined procedures, including venous reconstruction and biliary reconstruction. Finally, the remaining 218 patients were evaluated. Tumor-related variables, including tumor location, maximum tumor size, vascular invasion, tumor thrombus, tumor number, presence of ascites, lymph node metastasis, and extrahepatic metastases, were evaluated using imaging techniques, such as ultrasonography, multidetector-row computed tomography (CT), and dynamic contrast-enhanced magnetic resonance imaging. HCC was diagnosed in all patients based on pathology after hepatectomy. None of the patients received preoperative chemotherapy or postoperative adjuvant therapy before recurrence.

The indication for and extent of liver resection were determined as follows: tumor number $\leq 4$, general condition fulfilling a performance status of $0-2$, and Child-Pugh classification A or B. Indocyanine green retention rate at 15 minutes (ICG-R15) was used for decision-making for the liver resection volume. The estimated liver resection volume and future remnant liver volume were calculated by CT; if the remnant liver volume was $<30 \%$ of the total liver volume, liver resection was not performed. The exclusion criteria for LLR were as follows: HCC with tumor size $>10 \mathrm{~cm}, \mathrm{HCC}$ with the appearance of tumor thrombus in the main portal and main hepatic veins, or HCC necessary for liver resection of more than three contiguous segments. The selection criteria for laparoscopic approach were dependent on the surgeon's judgment.

This study was conducted in accordance with the Declaration of Helsinki and was approved by the institutional review board of Fukuyama City Hospital (permission number 452). The need to obtain informed consent from patients was waived based on the aim and methods of this study. All procedures in this study were carried out in accordance with relevant guidelines and regulations.

\section{Operative technique: laparoscopic liver resection}

LLR was performed with the patient in supine position for tumor location in the left lobe and left hemi-lateral position for tumor location in the right lobe. The pneumoperitoneum was kept by carbon dioxide maintained at approximately $10 \mathrm{mmHg}$ and all patients underwent intraoperative ultrasonography (IOUS) to clarify the locations of tumor and vascular structures. A 10-mm flexible camera was placed above the umbilicus, and 2-3 additional trocars, sized 5 or $12 \mathrm{~mm}$, were placed on this arrangement in each case. The parenchymal dissection was performed using ultrasonic coagulating shears and the Cavitron ultrasonic surgical aspirator (CUSA; Valleylab, Boulder, CO, USA). Vessels with diameters of $>3 \mathrm{~mm}$ were occluded using titanium clip, and the major hepatic vessels or hilar structures were divided by vascular stapling techniques. Temporary vascular inflow occlusion (Pringle maneuver) was applied during parenchymal transection depending on the situation in each case. The specimen was extracted through a small median incision with a plastic bag. A local drainage tube was placed during the operation and removed within 48-72 hours. 


\section{Operative technique: open liver resection}

For OLR, the patient was placed in supine position and the usual skin incision was an upward midline or reversed L-shaped laparotomy. Similar to LLR, IOUS was routinely performed and hepatic parenchymal dissection was performed using ultrasonic coagulating shears and CUSA with the Pringle maneuver. Vessels with diameters of $>3$ $\mathrm{mm}$ were ligated or sutured. An abdominal drain was placed during surgery and removed within 48-72 h, similar to LLR.

\section{Data collection}

We evaluated the following patient demographic data: age, sex, body mass index (BMI), American Society of Anesthesiologists (ASA) classification, and comorbid diseases (diabetes mellitus, hypertension, cardiovascular disease, respiratory disease, renal failure). We also obtained the medication history of antiplatelet therapy and of aspirin prescription for the primary and secondary prevention of thromboembolic morbidity in the year before date of surgery. With increasing age, elderly people are more likely to be prescribed antiplatelet therapy. Our institution has continued aspirin therapy perioperatively in patients undergoing liver resection to reduce thrombotic morbidity and has collected morbidity data on postoperative hemorrhage complications.

Blood samples for evaluating the operative liver function are as follows: aspartate aminotransferase (AST), alanine aminotransferase (ALT), serum platelet count, prothrombin time, serum concentrations of albumin, total bilirubin, protein induced by vitamin K absence, alpha-fetoprotein, ICG-R15, and Child-Pugh score.

Perioperative data, including surgical procedure, operative time, blood loss, blood transfusion rate, time to start oral intake, length of hospital stay, morbidity, and mortality, were evaluated. To classify the degree of chronic hepatitis, the degree of liver fibrosis and necroinflammation was classified based on the New Inuyama classification [16].

Surgical complication was defined according to Clavien-Dindo classification, which defines major complications as those graded greater than III [17]. Clinicopathological staging was determined based on the tumor/nodes/metastasis (TNM) classification.

\section{Statistical analysis}

\section{Propensity score matching}

As this study was not randomized for surgical procedure between LLR and OLR, it was necessary to achieve comparability between both groups regarding potential confounding variables. Therefore, we used PSM with a multivariable logistic regression model. The covariates included in this model were age, sex, BMI, comorbid diseases, history of aspirin prescription, ASA classification, hepatitis status, Child-Pugh classification, maximum tumor size, preoperative blood test, and surgical procedures (Table 1).

These covariates were chosen because they were previously used in other similar studies $[14,18,19]$ due to their clinical relevance. The nearest-neighbor matching algorithm was employed to form pairs of patients undergoing LLR and OLR to mitigate the potential for selection bias across surgical approaches. Case matching was performed one-to-one with a caliper width of 0.2 standard deviation $n$ of logit of the propensity score. 
Statistical analyses were performed using the JMP software version 14 (SAS Institute, Inc., Cary, NC, USA). Continuous variables before matching are described as median with range, whereas categorical data are expressed as number or frequency (\%). Comparisons between the two groups were conducted using MannWhitney U test. Differences in categorical outcomes were analyzed using chi-square test, Yates' test, Poisson distribution analysis, or Fisher's exact test. Post-matching variables between the groups were assessed using the paired t-test or Mann-Whitney $U$ test for continuous variables and the McNemar test for categorical variables. The level of statistical significance was set at 0.05 .

\section{Results}

\section{Patient characteristics}

Baseline characteristics of patients are summarized in Table 1. After PSM with a multivariable logistic regression model, 56 patients were selected for each group (LLR and OLR). The groups were well matched for all covariates in this model. No significant difference in baseline characteristics was noted between the groups after PSM. Additionally, both groups had a high rate of aspirin intake after PSM (OLR, 14.3\%; LLR, 10.7\%; $P=0.668)$.

\section{Operative variables}

After PSM, the LLR group exhibited a significantly shorter hospital stay (OLR: 12 days; LLR: 7 days; $P<0.001$ ) and lower blood loss (OLR: $327 \mathrm{~mL}$; LLR: $50 \mathrm{~mL}$; $P<0.001)$ (Table 2). The time to start oral intake was significantly shorter in the LLR group (OLR: 2 days; LLR: 1 day; $P<0.001)$. Furthermore, the blood transfusion rate was lower in the LLR group (OLR, 10.7\%; LLR, $0 \% ; P=0.012$ ). Although the operative time tended to be longer in the LLR group than in the OLR group, no significant difference was apparent (OLR, 214 min; LLR, 254 min; $P=0.074)$. In addition, histological data, including histology and background liver characteristics, were similar between the groups. None of the 56 patients in the LLR group needed to convert to open surgery.

\section{Postoperative complications of the OLR group and LLR group}

Postoperative complications are summarized in Table 3. After PSM, the rates of postoperative Clavien-Dindo I-II and Clavien-Dindo III-V complications did not significantly differ between the OLR and LLR groups $(P>0.05)$.

One patient in the LLR group experienced hemorrhage after receiving an anticoagulant, which is a coagulation factor $X$ inhibitor, for his cardiovascular disease (ischemic heart disease, atrial fibrillation, and installed pacemaker) at an early postoperative period; however, he did not undergo re-laparotomy and recovered with conservative treatment.

None of the patients were prescribed aspirin therapy except for the abovementioned patient who had postoperative hemorrhage. No significant difference in 90-day mortality rates was evident between the groups (OLR group, 3.2\%; LLR group, 0). One patient in the OLR group died from necrotizing fasciitis; he was infected with Aeromonas hydrophila, which is known to infect immunocompromised patients with hepatobiliary disease.

Despite repeated surgical debridement and intensive medical treatment, he died of multiple organ failure at 7 days after the initial operation.

\section{Discussion}


In the current study, we demonstrated that there were no significant differences in the overall postoperative complications between LLR and OLR. Furthermore, postoperative parameters, including blood loss, time to start oral intake, and length of postoperative hospital stay, were significantly lower or shorter with LLR. These results suggested that LLR for HCC offers a superior perioperative result to OLR in elderly patients.

We found that postoperative complications were not statistically different between the two groups. We also found low overall complications, regardless of high comorbidities, including $14.3 \%$ with cardiovascular disease and high ASA classification in accordance with recent published data $[19,20]$. Furthermore, blood loss and the length of hospital stay were significantly lower and shorter, respectively, in the LLR group than in the OLR group. Several studies have previously reported on the feasibility and safety of LLR as treatment for HCC in patients aged $\geq$ 70 years $[14,15]$.

In our study, 14 patients in both groups (12.5\%) were prescribed aspirin for the secondary prevention of ischemic stroke and cardiovascular disease. None of them underwent re-laparotomy or experienced postoperative hemorrhage. We had previously reported that continuing aspirin is safe and does not increase the risk of serious hemorrhagic complications after surgery [21-23]. Even in elderly patients, OLR and LLR were safely performed without interruption of aspirin therapy. These results could be attributed to secure improvements in surgical technique, surgical equipment, and careful follow-up for postoperative management.

Additionally, we found that the LLR group had earlier oral intake than the OLR group, indicating a faster bowel function recovery after LLR in elderly patients. A small surgical incision may lead to decreased postoperative pain and early postoperative bowel function recovery [6].

Pneumoperitoneum pressure and lower central venous pressure (CVP) in laparoscopy aid in controlling backflow bleeding from the hepatic vein [24]. On the other hand, chronic obstructive pulmonary disease (COPD), which is often found in elderly patients, poses higher risk for postoperative respiratory complications. In patients with COPD, airway obstruction results in an increase in intrathoracic pressure [25]. Furthermore, laparoscopic pneumoperitoneum exacerbates the CVP elevation in patients with COPD. A recent research in piglets revealed that bleeding from the hepatic vein cannot be controlled by increasing the pneumoperitoneum pressure when the airway and/or intrathoracic pressure is high [25]. For this reason, the indication for LLR in elderly patients with COPD should be carefully considered. Furthermore, high pneumoperitoneum pressure with LLR is a risk factor associated with higher rates of pulmonary carbon dioxide gas embolism, which may induce adverse respiratory and cardiovascular events $[26,27]$.

The current study is associated with some limitations, including the relatively small sample size, single-center design, and lack of long-term follow-up results. The major limitation is that we used PSM analysis, which may not be able to balance unmeasured confounding factors. In the PSM, one-to-one PSM was used in large samples. Given the small sample size, one-to-one PSM may bias the results [28]. However, a randomized controlled trial (RCT) would be considered less biased than observational studies, the high risk of postoperative morbidities with elderly patients may limit the inclusion in a RCT.

In conclusion, we demonstrated herein that LLR for HCC in elderly patients is a safe and effective technique with respect to bowel function recovery, length of hospital stay, and blood loss, without the risk of increasing intra- or postoperative morbidity, compared to OLR. Therefore, we conclude that advanced age alone is not a contraindication for LLR; however, the selection of each patient for surgery should be carefully assessed, with 
consideration of comorbidity conditions to avoid postoperative complications. Further investigation is necessary to assess the long-term outcomes of LLR in elderly patients.

\section{Declarations}

\section{Data availability:}

The datasets generated during and/or analysed during the current study are available from the corresponding author on reasonable request.

\section{Acknowledgements:}

No preregistration exists for the studies reported in this article.

\section{Author contributions:}

Kazuteru Monden wrote the main manuscript text and tables. Masayoshi Hioki, Hiroshi Sadamori, Satoshi Ohno, and Norihisa Takakura helped to design study and agreed on final draft.

\section{Competing Interests}

The authors declare no competing interests.

\section{References}

1. Ferenci, P., et al. Hepatocellular carcinoma (HCC): A global perspective. J. Clin. Gastroenterol. 44, 239-245 (2010).

2. American Cancer Society. Liver cancer risk factors. Preprint at http://www.cancer.org/cancer/livercancer/detailedguide/liver-cancer-risk-factors (2016).

3. Gagner, M. Laparoscopic partial hepatectomy for liver tumor. Surg. Endosc. 6: 97-8 (1992).

4. Martin, R. C. G., Scoggins, C. R. \& McMasters, K. M. Laparoscopic hepatic lobectomy: Advantages of a minimally invasive approach. J. Am. Coll. Surg. 210, 627-634 (2010).

5. Yin, Z., Fan, X., Ye, H., Yin, D. \& Wang, J. Short- and long-term outcomes after laparoscopic and open hepatectomy for hepatocellular carcinoma: A global systematic review and meta-analysis. Ann. Surg. Oncol. 20, 1203-1215 (2013).

6. Mirnezami, R., et al. Short- and long-term outcomes after laparoscopic and open hepatic resection: Systematic review and meta-analysis. HPB (Oxford). 13, 295-308 (2011).

7. Asahina, Y., et al. Effect of aging on risk for hepatocellular carcinoma in chronic hepatitis $\mathrm{C}$ virus infection. Hepatology. 52, 518-527 (2010).

8. Wynne, H. A., et al. The effect of age upon liver volume and apparent liver blood flow in healthy man. Hepatology. 9, 297-301 (1989).

9. Zoli, M., et al. Portal blood velocity and flow in aging man. Gerontology. 35, 61-65 (1989).

10. Marchesini, G., et al. Galactose elimination capacity and liver volume in aging man. Hepatology. 8, 1079-1083 (1988). 
11. Fan, H-L., et al. Advanced age is not a contraindication for liver resection in cases of large hepatocellular carcinoma. Eur. J. Surg. Oncol. 40, 214-219 (2014).

12. Hsu, K-F., et al. Long-term outcomes in elderly patients with resectable large hepatocellular carcinoma undergoing hepatectomy. Surg. Oncol. 27, 595-601 (2018).

13. Okamura, Y., et al. The short- and long-term outcomes in elderly patients with hepatocellular carcinoma after curative surgery: A case-controlled study with propensity score matching. Eur. Surg. Res. 59, 380-390 (2018).

14. Wang, X-T., et al. Pure laparoscopic versus open liver resection for primary liver carcinoma in elderly patients: A single-center, case-matched study. Medicine (Baltimore). 94, e1854 (2015).

15. Chan, A. C. Y., et al. Laparoscopic versus open liver resection for elderly patients with malignant liver tumors: A single-center experience. J. Gastroenterol. Hepatol. 29, 1279-1283 (2014).

16. Tomimaru, Y., et al. Fibrosis in non-cancerous tissue is the unique prognostic factor for primary hepatocellular carcinoma without Hepatitis B or C viral infection. World. J. Surg. 30: 1729-1735 (2006).

17. Dindo, D., Demartines, N., \& Clavien, P-A. Classification of surgical complications: A new proposal with evaluation in a cohort of 6336 patients and results of a survey. Ann. Surg. 240, 205-213 (2004).

18. Chen, J., Li, H., Liu, F., Li, B., \& Wei, Y. Surgical outcomes of laparoscopic versus open liver resection for hepatocellular carcinoma for various resection extent. Med (United States). 96, 1-6 (2017).

19. Nomi, T., et al. Laparoscopic major hepatectomy for colorectal liver metastases in elderly patients: A singlecenter, case-matched study. Surg. Endosc. 29, 1368-1375 (2015).

20. Tzeng, C-W. D., Cooper, A. B., Vauthey, J-N., Curley, S. A., \& Aloia, T.A. Predictors of morbidity and mortality after hepatectomy in elderly patients: Analysis of 7621 NSQIP patients. HPB (Oxford). 16, 459-468 (2014).

21. Ono K, et al. Effect of aspirin continuation on blood loss and postoperative morbidity in patients undergoing laparoscopic cholecystectomy or colorectal cancer resection. Surg. Laparosc. Endosc. Percutan. Tech. 23, 97100 (2013).

22. Ono, K., Hidaka, H., Sato, M., \& Nakatsuka, H. Preoperative continuation of aspirin administration in patients undergoing major abdominal malignancy surgery. J. Anesth. 33, 90-95 (2019).

23. Monden, K., et al. Safety and feasibility of liver resection with continued antiplatelet therapy using aspirin. J. Hepatobiliary Pancreat. Sci. 375-381 (2017).

24. Jones, R. M., Moulton, C. E., \& Hardy, K.J. Central venous pressure and its effect on blood loss during liver resection. Br. J. Surg. 85, 1058-1060 (1998).

25. Kobayashi, S., et al. An experimental study on the relationship among airway pressure, pneumoperitoneum pressure, and central venous pressure in pure laparoscopic hepatectomy. Ann. Surg. 263, 1159-1163 (2016).

26. Otsuka, Y., et al. Gas embolism in laparoscopic hepatectomy: What is the optimal pneumoperitoneal pressure for laparoscopic major hepatectomy? J. Hepatobiliary Pancreat. Sci. 20, 137-140 (2013).

27. Eiriksson, K., Fors, D., Rubertsson, S., \& Arvidsson, D. High intra-abdominal pressure during experimental laparoscopic liver resection reduces bleeding but increases the risk of gas embolism. Br. J. Surg. 98, 845-852 (2011).

28. Holmes, W., Olsen, L. Using propensity scores with small samples. Inannual meetings of the American Evaluation Association. San Antonio, Texas 2010.Preprint at http://www.faculty.umb.edu/william_holmes/usingpropensityscoreswithsmallsamples.pdf (2014). doi: 10.13140/2.1.2255.0724. 


\section{Tables}

\section{Table 1}

Demographic and clinical data of patients before and after propensity score matching 


\begin{tabular}{|c|c|c|c|c|c|c|c|c|c|c|}
\hline \multirow[b]{3}{*}{ Age, years } & \multicolumn{5}{|c|}{ Before matching } & \multicolumn{5}{|c|}{ After matching } \\
\hline & \multicolumn{2}{|c|}{$\begin{array}{l}\text { OLR } \\
(n=138)\end{array}$} & \multicolumn{2}{|c|}{$\begin{array}{l}\text { LLR } \\
(n=80)\end{array}$} & \multirow{2}{*}{$\begin{array}{l}P \\
0.879\end{array}$} & \multicolumn{2}{|c|}{$\begin{array}{l}\text { OLR } \\
(n=56)\end{array}$} & \multicolumn{2}{|c|}{$\begin{array}{l}\text { LLR } \\
(n=56)\end{array}$} & \multirow{2}{*}{$\begin{array}{l}P \\
0.852\end{array}$} \\
\hline & 76 & $\begin{array}{l}{[70-} \\
90]\end{array}$ & 75 & $\begin{array}{l}{[70-} \\
84]\end{array}$ & & 75 & $\begin{array}{l}{[70-} \\
90]\end{array}$ & 75 & $\begin{array}{l}{[70-} \\
83]\end{array}$ & \\
\hline Male sex & 97 & (70.3) & 57 & (71.3) & 0.881 & 38 & $(67.9)$ & 36 & $(64.3)$ & 0.690 \\
\hline $\mathrm{BMI}, \mathrm{kg} / \mathrm{m}^{2}$ & 22.7 & $\begin{array}{l}{[15.3-} \\
32.0]\end{array}$ & 22.8 & $\begin{array}{l}{[17.5-} \\
34.5]\end{array}$ & 0.998 & 23.1 & $\begin{array}{l}{[15.3-} \\
32.0]\end{array}$ & 22.6 & $\begin{array}{l}{[17.5-} \\
34.5]\end{array}$ & 0.384 \\
\hline \multicolumn{11}{|l|}{$\begin{array}{l}\text { Preexisting } \\
\text { medical } \\
\text { condition }\end{array}$} \\
\hline Hypertension & 73 & $(52.9)$ & 54 & $(67.5)$ & 0.035 & 34 & $(60.7)$ & 36 & $(64.3)$ & 0.696 \\
\hline $\begin{array}{l}\text { Diabetes } \\
\text { mellitus }\end{array}$ & 47 & (34.1) & 30 & $(37.5)$ & 0.608 & 22 & (39.3) & 20 & $(35.7)$ & 0.696 \\
\hline Renal failure & 12 & (8.7) & 8 & $(10.0)$ & 0.748 & 4 & (7.1) & 4 & $(7.1)$ & 1.00 \\
\hline $\begin{array}{l}\text { Ischemic } \\
\text { heart disease }\end{array}$ & 29 & $(21.0)$ & 11 & (13.8) & 0.182 & 7 & $(12.5)$ & 9 & $(16.1)$ & 0.589 \\
\hline $\begin{array}{l}\text { COPD or } \\
\text { pulmonary } \\
\text { disease }\end{array}$ & 10 & (7.3) & 8 & $(10.0)$ & 0.477 & 4 & (7.1) & 5 & (8.9) & 0.728 \\
\hline $\begin{array}{l}\text { Antiplatelet } \\
\text { (aspirin) intake, } \\
\text { n (\%) }\end{array}$ & 18 & $(13.0)$ & 10 & $(12.5)$ & 0.908 & 8 & (14.3) & 6 & $(10.7)$ & 0.568 \\
\hline $\begin{array}{l}\text { ASA } \\
\text { classification }\end{array}$ & & & & & 0.051 & & & & & 0.839 \\
\hline 1 & 0 & $(0)$ & 0 & (0) & & 0 & (0) & 0 & (0) & \\
\hline II & 80 & $(58.0)$ & 57 & (71.3) & & 39 & $(69.6)$ & 38 & $(67.9)$ & \\
\hline III & 58 & $(42.0)$ & 23 & $(28.7)$ & & 17 & $(30.4)$ & 18 & $(32.1)$ & \\
\hline Hepatitis status & & & & & 0.702 & & & & & 0.803 \\
\hline HBV positive & 20 & $(14.5)$ & 17 & $(21.2)$ & & 7 & $(12.5)$ & 12 & $(21.4)$ & \\
\hline HCV positive & 73 & $(52.9)$ & 38 & $(47.5)$ & & 30 & $(53.6)$ & 27 & $(48.2)$ & \\
\hline $\begin{array}{l}\text { HBV HCV } \\
\text { positive }\end{array}$ & 2 & (1.4) & 1 & (1.3) & & 0 & (0) & 0 & (0) & \\
\hline $\begin{array}{l}\text { HBV HCV } \\
\text { negative }\end{array}$ & 43 & $(31.2)$ & 24 & $(30.0)$ & & 19 & (33.9) & 17 & $(30.4)$ & \\
\hline Child-Pugh & & & & & 0.981 & & & & & 1.000 \\
\hline
\end{tabular}


classification

\begin{tabular}{|c|c|c|c|c|c|c|c|c|c|c|}
\hline$A$ & 131 & (95.0) & 76 & $(95.0)$ & & 52 & $(92.9)$ & 52 & (92.9) & \\
\hline B & 7 & $(5.0)$ & 4 & $(5.0)$ & & 4 & $(7.1)$ & 4 & $(7.1)$ & \\
\hline $\begin{array}{l}\text { AFP level } \\
\text { (ng/mL) }\end{array}$ & 10 & $\begin{array}{l}{[2.0-} \\
113560]\end{array}$ & 7.5 & $\begin{array}{l}{[2-} \\
8900]\end{array}$ & 0.358 & 10 & $\begin{array}{l}{[2.0-} \\
14198]\end{array}$ & 9.5 & $\begin{array}{l}{[2-} \\
8900]\end{array}$ & 0.782 \\
\hline $\begin{array}{l}\text { PIVKA-II level } \\
(\mathrm{mAU} / \mathrm{mL})\end{array}$ & 100 & $\begin{array}{l}{[10-} \\
115454]\end{array}$ & 40 & $\begin{array}{l}{[2.8-} \\
24892]\end{array}$ & 0.036 & 36 & $\begin{array}{l}{[10-} \\
37236]\end{array}$ & 64 & $\begin{array}{l}{[10-} \\
24892]\end{array}$ & 0.141 \\
\hline $\operatorname{PLT}\left(' 10^{4} / \mu \mathrm{L}\right)$ & 14.5 & $\begin{array}{l}{[3.2-} \\
47.4]\end{array}$ & 15.0 & [4-36] & 0.523 & 15.1 & $\begin{array}{l}{[5.1-} \\
46.6]\end{array}$ & 15.0 & $\begin{array}{l}{[5.7-} \\
33.9]\end{array}$ & 0.635 \\
\hline ALB $(g / L)$ & 3.9 & $\begin{array}{l}{[2.8-} \\
4.7]\end{array}$ & 4.2 & $\begin{array}{l}{[2.8-} \\
5.0]\end{array}$ & $<0.001$ & 4.1 & $\begin{array}{l}{[3.2-} \\
4.7]\end{array}$ & 4.0 & $\begin{array}{l}{[2.8-} \\
5.0]\end{array}$ & 0.290 \\
\hline T-Bil (mg/L) & 0.65 & $\begin{array}{l}{[0.2-} \\
2.2]\end{array}$ & 0.6 & $\begin{array}{l}{[0.2-} \\
1.9]\end{array}$ & 0.912 & 0.7 & $\begin{array}{l}{[0.3-} \\
2.2]\end{array}$ & 0.6 & $\begin{array}{l}{[0.2-} \\
1.9]\end{array}$ & 0.489 \\
\hline ALT (IU/L) & 26 & $\begin{array}{l}{[6-} \\
175]\end{array}$ & 25 & $\begin{array}{l}{[2-} \\
227]\end{array}$ & 0.697 & 24 & $\begin{array}{l}{[8-} \\
175]\end{array}$ & 24 & $\begin{array}{l}{[2-} \\
227]\end{array}$ & 0.977 \\
\hline AST (IU/L) & 33 & $\begin{array}{l}{[12-} \\
327]\end{array}$ & 32 & $\begin{array}{l}{[15-} \\
177]\end{array}$ & 0.498 & 30 & $\begin{array}{l}{[15-} \\
206]\end{array}$ & 32 & $\begin{array}{l}{[16-} \\
177]\end{array}$ & 0.825 \\
\hline $\begin{array}{l}\text { Prothrombin } \\
\text { time (\%) }\end{array}$ & 87 & $\begin{array}{l}{[60-} \\
100]\end{array}$ & 88 & $\begin{array}{l}{[69-} \\
100]\end{array}$ & 0.415 & 88 & $\begin{array}{l}{[64-} \\
100]\end{array}$ & 87 & $\begin{array}{l}{[69-} \\
100]\end{array}$ & 0.612 \\
\hline ICG-R15 (\%) & 13.8 & $\begin{array}{l}{[3.2-} \\
35.4]\end{array}$ & 14.2 & $\begin{array}{l}{[3.6-} \\
43.1]\end{array}$ & 0.924 & 13.9 & $\begin{array}{l}{[4.7-} \\
32.8]\end{array}$ & 14.0 & $\begin{array}{l}{[3.6-} \\
35.3]\end{array}$ & 0.758 \\
\hline $\begin{array}{l}\text { Size of the } \\
\text { largest tumor } \\
(\mathrm{mm})\end{array}$ & 27.0 & $\begin{array}{l}{[1.6-} \\
170]\end{array}$ & 22.5 & $\begin{array}{l}{[1.4-} \\
65]\end{array}$ & 0.008 & 21.0 & $\begin{array}{l}{[1.6-} \\
80]\end{array}$ & 24.5 & $\begin{array}{l}{[1.4-} \\
65]\end{array}$ & 0.677 \\
\hline $\begin{array}{l}\text { Number of } \\
\text { tumors }\end{array}$ & 1 & {$[1-4]$} & 1 & [1-3] & 0.893 & 1 & {$[1-3]$} & 1 & [1-3] & 0.830 \\
\hline $\begin{array}{l}\text { Surgical } \\
\text { procedure, n (\%) }\end{array}$ & & & & & $<0.001$ & & & & & 0.971 \\
\hline $\begin{array}{l}\quad \text { Limited } \\
\text { partial resection } \\
\text { or lateral } \\
\text { sectionectomy }\end{array}$ & 49 & (35.5) & 51 & $(63.7)$ & & 31 & $(55.4)$ & 32 & (57.2) & \\
\hline Segmentectomy & 28 & $(20.3)$ & 16 & $(20.0)$ & & 14 & $(25.0)$ & 13 & $(23.2)$ & \\
\hline Sectionectomy & 32 & $(23.2)$ & 7 & $(8.8)$ & & 7 & $(12.5)$ & 6 & $(10.7)$ & \\
\hline $\begin{array}{l}\text { Lobectomy or } \\
\text { more than three } \\
\text { segmentectomy }\end{array}$ & 29 & $(21.0)$ & 6 & $(7.5)$ & & 4 & $(7.1)$ & 5 & $(8.9)$ & \\
\hline
\end{tabular}

Data are presented as the number of patients (\%) or the median value of parameters [range]. AFP, alphafetoprotein; ALB, albumin; ALT, alanine transferase; ASA, American Society of Anesthesiologists; I = normal 
healthy patient; II = patient with mild systemic disease; III = patient with severe systemic disease that is not incapacitating; AST, aspartate aminotransferase; BMI, body mass index; HBV, hepatitis B virus; HCV, hepatitis C virus; ICG-R15, indocyanine green retention rate at $15 \mathrm{~min}$; LLR, laparoscopic liver resection; N/A, not applicable; OLR, open liver resection; PIVKA-II, protein induced by vitamin K absence; PLT, platelets; T-Bil, total bilirubin.

\section{Table 2}

Operative parameters of patients in matched cohorts of laparoscopic and open liver resection

\begin{tabular}{|c|c|c|c|c|c|}
\hline \multirow[b]{2}{*}{ Operative time (min) } & \multicolumn{2}{|c|}{$\begin{array}{l}\text { OLR } \\
(n=56)\end{array}$} & \multicolumn{2}{|c|}{$\begin{array}{l}\text { LLR } \\
(n=56)\end{array}$} & \multirow{2}{*}{$\begin{array}{l}P \\
0.074\end{array}$} \\
\hline & 214 & {$[77-436]$} & 254 & [105-623] & \\
\hline Conversion, n (\%) & & & 0 & $(0)$ & N/A \\
\hline Blood loss (mL) & 327 & {$[10-1370]$} & 50 & {$[0-750]$} & $<0.001$ \\
\hline Blood transfusion rate, n (\%) & 6 & $(10.7)$ & 0 & $(0)$ & 0.012 \\
\hline Duration of drainage tube (days) & 2 & {$[0-28]$} & 2 & {$[0-18]$} & 0.386 \\
\hline Time to start oral intake (days) & 2 & {$[1-8]$} & 1 & {$[1-7]$} & $<0.001$ \\
\hline Length of hospital stay (days) & 12 & {$[7-107]$} & 7 & {$[4-84]$} & $<0.001$ \\
\hline Histology & & & & & 0.122 \\
\hline Well differentiated & 31 & $(55.4)$ & 32 & $(57.1)$ & \\
\hline Moderately differentiated & 21 & $(37.5)$ & 24 & $(42.9)$ & \\
\hline Poorly differentiated & 4 & $(7.1)$ & 0 & $(0)$ & \\
\hline Microvascular invasion, n (\%) & 7 & $(12.5)$ & 6 & $(10.7)$ & 0.768 \\
\hline \multicolumn{6}{|l|}{ Background liver characteristics } \\
\hline F3-F4 & 19 & $(33.9)$ & 23 & $(41.1)$ & 0.435 \\
\hline $\mathrm{A} 2$ & 16 & $(28.6)$ & 9 & $(16.1)$ & 0.112 \\
\hline UICC TNM classification & & & & & 0.382 \\
\hline Stage IA & 24 & $(42.9)$ & 23 & $(41.0)$ & \\
\hline Stage IIB & 20 & $(35.7)$ & 24 & $7(48.2)$ & \\
\hline Stage II & 6 & $(10.7)$ & 3 & $(5.4)$ & \\
\hline Stage IIIA & 6 & $(10.7)$ & 3 & $(5.4)$ & \\
\hline
\end{tabular}

Data are presented as the number of patients (\%) or the median value of parameters [range]. The grade of fibrosis was classified based on the New Inuyama classification: F3 = bridging fibrosis plus lobular distortion, F4 = liver cirrhosis. The grade of necroinflammation was classified: $A 2$ = moderate. N/A, not applicable. 
Postoperative outcomes of patients in matched cohorts of laparoscopic and open liver resection

\begin{tabular}{|c|c|c|c|c|c|}
\hline \multirow[b]{2}{*}{ Clavien-Dindo I- II complications n (\%) } & \multicolumn{2}{|c|}{$\begin{array}{l}\text { OLR } \\
(n=56)\end{array}$} & \multicolumn{2}{|c|}{$\begin{array}{l}\text { LLR } \\
(n=56)\end{array}$} & \multirow{2}{*}{$\begin{array}{l}P \\
0.293\end{array}$} \\
\hline & 10 & $(19.2)$ & 6 & $(11.8)$ & \\
\hline Clavien-Dindo III-V complications n (\%) & 4 & (7.1) & 5 & $(8.9)$ & 0.728 \\
\hline Ascites & 0 & (0) & 1 & $(1.8)$ & \\
\hline Respiratory infection & 1 & (1.8) & 1 & (1.8) & \\
\hline Bile leakage & 2 & (3.6) & 1 & (1.8) & \\
\hline Organ/space SSI & 0 & (0) & 1 & $(1.8)$ & \\
\hline Necrotizing fasciitis & 1 & $(1.8)$ & 0 & (0) & \\
\hline Hemorrhage & 0 & (0) & 1 & $(1.8)$ & \\
\hline $\begin{array}{l}\text { Liver failure by ISGLS criteria } \\
\text { >Grade C }\end{array}$ & 0 & (0) & 0 & (0) & \\
\hline 90-day mortality, n (\%) & 1 & $(3.2)$ & 0 & (0) & 0.315 \\
\hline
\end{tabular}

Data are presented as the number of patients (\%) or the median value of parameters [range]. ISGLS, International Study Group for Liver Surgery; SSI, surgical site infection; N/A, not applicable 